\title{
Maternal and Neonatal Risk Factors of Low Birth Weight in Guwahati Metro, Assam, Northeast India
}

\author{
Nirmali Gogoi* \\ Department of Child Health Nursing, Assam down town University, India
}

Submission: January 07, 2018; Published: May 22, 2018

*Corresponding author: Nirmali Gogoi, Department of Child Health Nursing, Assam down town University, India, Tel: 9864082452;

Email: nirmali.gogoi111@gmail.com

\begin{abstract}
Introduction and objectives:Birth weight is an important determinant of child survival and development. Low birth weight is an index of our status of public health, maternal health and nutrition. The major challenge in the field of public health is to identify the factors influencing low birth weight and to institute remedial measures. The study was attempted to assess prevalence of low birth weight and its risk factors affecting low birth weight was conducted among 300 mothers and their respective live born baby in GMCH, Guwahati metro, Assam.
\end{abstract}

Materials and methods: A cross sectional study design was carried out in a government hospital among 300mothers using interviewer administered questionnaire. All 300 postnatal mothers who delivered in the hospital during study period were included in the study except still births. All babies were weighted on standard beam balance within 24 hours of delivery and mother's height was measured by height measuring stand. Bivariate and multivariate logistic regression was employed to identify the predictors at $\mathrm{p}<0.001$ and $\mathrm{p}<0.05$.

Results and analysis: The prevalence of low birth weight was found as $26.0 \%$ (95\%, CL=21.36-31.24) in 300 samples. Low birth weight was significantly associated with maternal age $<18$ years $(\mathrm{OR}=3.0695 \% \mathrm{Cl}=1.24-3.52)$, height of the mother $<145 \mathrm{~cm}(\mathrm{OR}=2.7295 \% \mathrm{CL}=1.61$ 4.62), history of ANC visit $<3(\mathrm{OR}=1.9095 \% \mathrm{Cl}=1.03-3.52)$, history of high risk behavior(use of tobacco) (OR=8.84 95\%Cl=0.91-86.28), multiple pregnancy $(\mathrm{OR}=5.9595 \% \mathrm{Cl}=1.07-33.13)$, gestational age $<37$ weeks (OR=10.00 95\% $\mathrm{Cl}=4.53-22.09)$, normal mode of delivery $(\mathrm{OR}=2.09$ $95 \% \mathrm{Cl}=1.24-3.52)$. Female child $(\mathrm{OR}=1.02,95 \% \mathrm{Cl}=0.61-1.72)$ and preterm birth $(\mathrm{OR}=10.00,95 \% \mathrm{Cl}=4.53-22.09)$, weight gain during pregnancy $<6 \mathrm{~kg}(\mathrm{OR}=1.9895 \% \mathrm{Cl}=0.88-4.44)$ were found to be higher risk of LBW.

Discussion and conclusion: The prevalence of low birth weight was found to be very high and it was associated with many risk factors related to maternal health and services. Hence it is recommended to improve maternal health through strengthening the existing maternal services at the basic level of community.

Keywords: Low birth weight; Maternal age; Parity; ANC visit; HB\% level; Gestational age; High risk behavior; GMCH.

\section{Introduction}

Birth weight is an important determinant of child survival and also growth and development. Low birth weight is a major public health problem in developing countries including in India. Low birth weight has been defined by the World health organization as birth weight of less than 2500gm. (WHO 1984) [1]. The prevalence of LBW in any population reflects its socio-economic development and status of public health. It is an indicator of future health and survival of child.

LBW contributes to $60 \%-80 \%$ of all neonatal death. The global prevalence of LBW is $15.5 \%$ which amount to about 20 millions LBW born each year, $95.5 \%$ of them in developing counties [2]. India is one of the countries with the highest incidence of LBW, which has nearly 7.5 millions LBW babies anually [3]. According to UNICEF estimate, almost every third newborn (30\%) in India is LBW [4]. Perinatal mortality among LBW infants is about eight times higher than that in infants weighing more than $2.5 \mathrm{~kg}$ [5]. LBW is not only major predictor of prenatal mortality and morbidity, but recent studies have found that LBW also increases risk for non-communicable diseases such as diabetes and cardiovascular disease later in life $[6,7]$.

The primary cause of LBW is premature birth, being born before 37 weeks of gestation; and another cause of low birth weight is intrauterine growth retardation. However, there are other factors that can also contribute to the risk of low birth weight. These includes: race, mother's age, multiple birth, mother's health, low socio-economic status [8].

The best way of prevention of low birth weight is prevention of preterm births. Prenatal care is a key factor in preventing preterm births and low birth weight babies. Maternal health like proper nutrition and weight gain are linked with fetal weight gain and 
birth weight. Mother should avoid alcohol, cigarettes and illicit drugs, which can contribute to poor fetal growth, among other complications.

\section{Materials and Methods}

A cross sectional study design was carried out in a tertiary care hospital, Guwahati Medical College Hospital (GMCH), Assam in 2016 from October to December. The study was conducted in the post-natal ward among 300 mothers delivering live born neonates in the hospital. The sample size 300 was calculated taking minimum 25\% prevalence of low birth weight with $20 \%$ of permissible error. Consecutive non-random sampling technique was used for selecting samples. Ethical permission was obtained from the hospital authority and verbal consent was taken from each sample. The babies were weighed on standard beam weighing machine up to $20 \mathrm{gm}$ accuracy within 24 hours of the birth. LBW was defined as a birth weight of $<2500 \mathrm{gm}$. Mother's height was measured up to the accuracy of $0.5 \mathrm{~cm}$ by height measuring stand. A predesigned and pretested structured interview schedule related to socio-demographic variables and the maternal risks factors of LBW among post-natal mothers were used for collecting information. The mothers whose were critically ill at the time of data collection and whose mothers had still birth baby were excluded from the study sample. The data collected was compiled, tabulated and subjected to statistical analysis wherever applicable. Statistical analysis was done using SPSS for windows, version 18.0. Bivariate and multivariate logistic regression was employed to identify the predictors at $\mathrm{P}<0.001$, and $\mathrm{p}<0.05$.

\section{Results and Discussion}

The prevalence of LBW in GMCH, Guwahati metro during the study period was 78 out of 300 cases corresponding to estimated prevalence $26 \%$ (95\% CI: $21.36 \%-31.24 \%$ ). The normal baby was $74 \%$ (95\% CI: 68.76\%-78.64\%). (Figure 1) The prevalence of low birth weight in the present study was $26.00 \%$ (95\% CI: $21.36 \%$ $31.24 \%$ ) where as overall, it is estimated $15 \%$ to $20 \%$ of all births worldwide are LBW. A similar prevalence $(27.2 \%)$ was reported by UNICEF global data base 2012 in Bihar. [9] Several supportive studies conducted in different part of the Assam reported 28.40\% by Krishnatreyal et al. [10], 21.8\% by Bora [11] 14.22\% by Baruah [12] and also reported the higher prevalence of low birth weight (31.3\%) in west Bengal [13] 40.0\% in Uttar Pradesh [14].
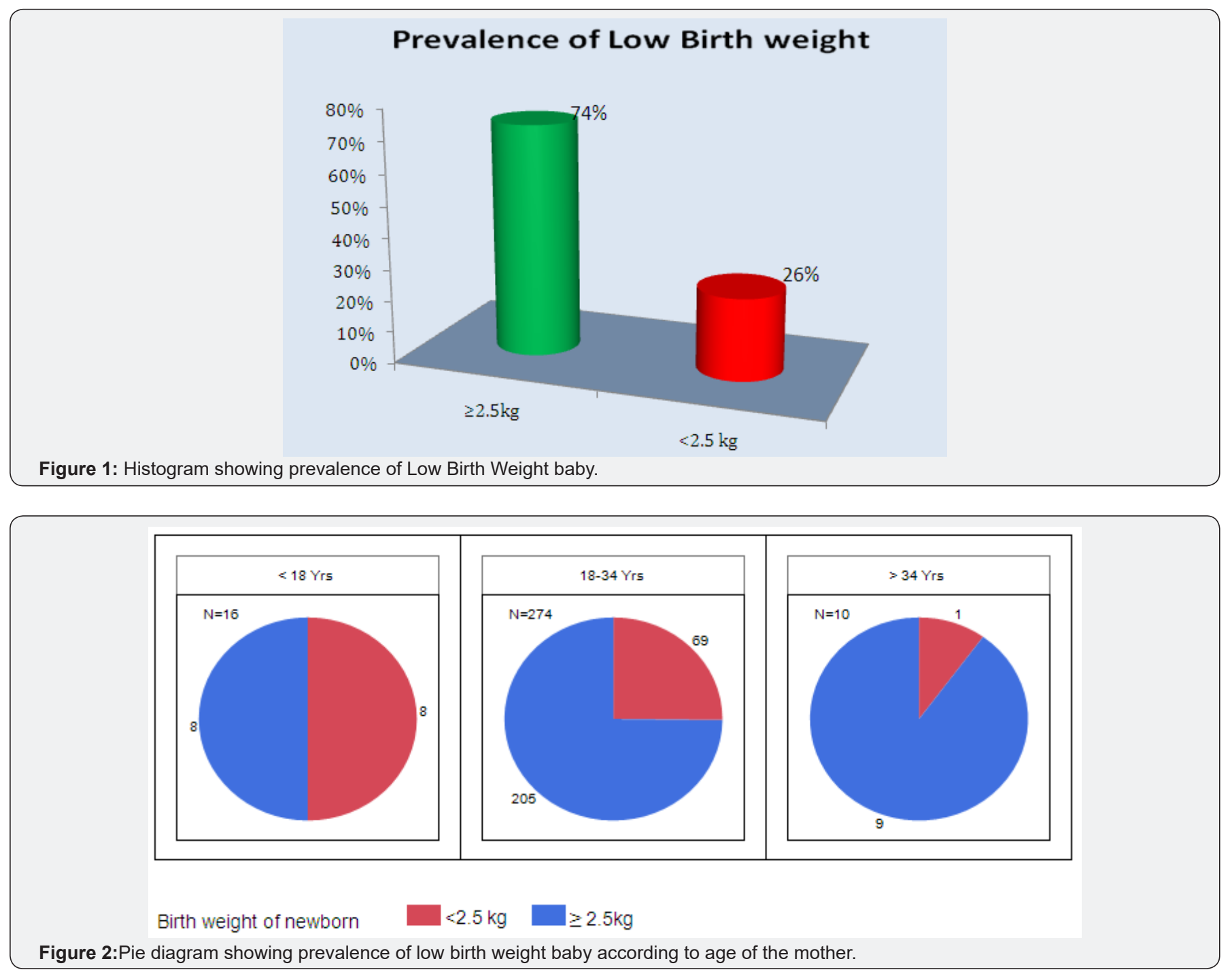
In place of residence, $81.00 \%$ of mothers from rural and $19.00 \%$ from urban. In regards of mother's educational status, $51.67 \%$ of mothers were literate, $48.33 \%$ were illiterate. As a indicator of socio-economic status, majority of respondents (47.33\%) had monthly income were Rs. 5001-10,000. Prevalence of low birth weight baby according to age of the mother, it was found that $2.7 \%$ (16) newborns belongs to the mothers of age group <18 years, $47 \%$ (74) newborns belongs to the mothers of age group 18-34 years and $1.3 \%$ (10) newborns belongs to age group above 35 years. The prevalence of LBW 50\% in the age group of $<18$ years, $25 \%$ in the age group of $18-34$ years and $10 \%$ at the age group of above 35 years (Figure 2). It is observed that the age of the mother affected the rate of LBW considerably. Incidence rate is highest among the younger mothers. This finding supported by Rahul et al. [15] Velankar [16] and Anand et al. [17].

Table 1: (ANOVA Table) $\mathrm{Hb} \%$ level during delivery with respect to birth weight of newborn.

\begin{tabular}{|c|c|c|c|c|c|}
\hline & Sum of Squares & df & Mean Square & F & P-value \\
\hline Between Groups & 1.844 & 1 & 1.844 & 0.814 & 0.368 \\
\hline Within Groups & 674.924 & 298 & 2.265 & & \\
\hline Total & 676.768 & 299 & & & \\
\hline
\end{tabular}

Table 2: Bivariate cross frequency of Maternal Risk Factors influencing low birth weight and chi square Test of Association.

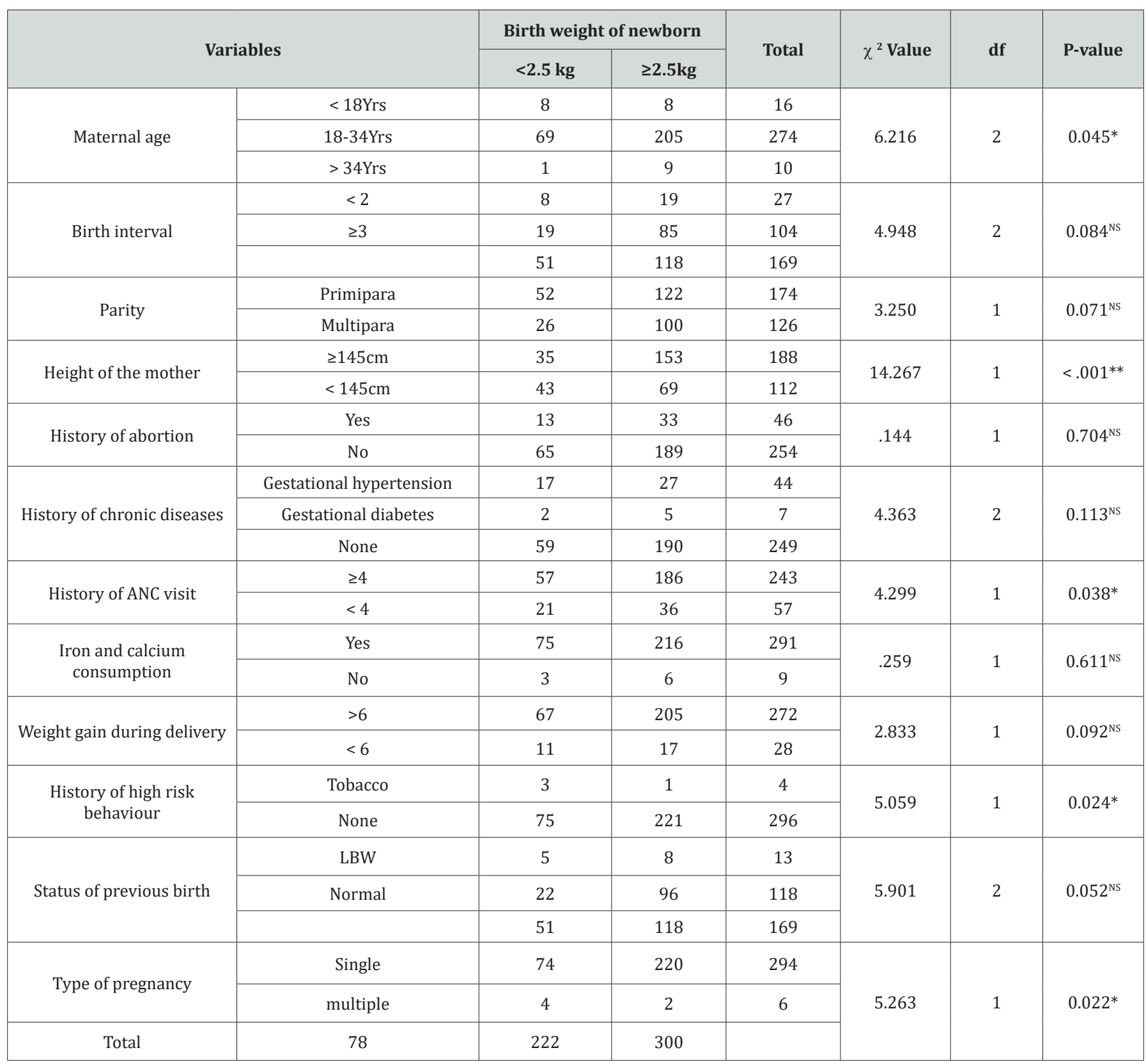


An analysis of variance showed that the effect of birth weight of newborn was insignificant on $\mathrm{Hb} \%$ level of mother during delivery, $F(1,298)=0.814, P=0.368$ (Figure 2). In other words, mother of low birth weight of newborn $(\mathrm{M}=10.23, \mathrm{SD}=1.52$, Range: 6.70-14.20) had same $\mathrm{Hb} \%$ level of mothers with normal birth weight of newborn, ( $M=10.41, S D=1.50$, Range: $5.10-14.90)$, $\mathrm{t}(298)=0.903, \mathrm{P}=0.368$ ( $\mathrm{two}$ tailed). It seems that overall $\mathrm{Hb} \%$ level of mothers both with low birth weight of newborn and with normal birth weight of newborn is very low (Table 1). A study by Kavitha B et al. reported that about $35.28 \%$ of mothers with low birth weight HB\% level was $10.9 \%$ and it was about two-third of the mothers were anemic [18].

A chi-square test of independence was performed to examine the relation between birth weight of newborn and maternal risk factors. The relation between birth weight of newborn was significant for maternal age $\chi^{2}(2, N=300)=6.216, P=0.045$, for height of the mother, $\chi^{2}(1, \mathrm{~N}=300)=14.267, \mathrm{P}<0.001$, history of ANC visit, $\chi^{2}(1, \mathrm{~N}=300)=4.299, \mathrm{P}=0.038$, history of high risk behavior, $\chi^{2}(1, N=300)=5.059, P=0.024$ and type of pregnancy, $\chi^{2}(1, N=300)=5.263, P=0.022$. However, rest of the variables viz. birth interval, parity, history of abortion, history of chronic diseases, iron and calcium consumption, weight gain during delivery, and status of previous birth were insignificantly related to birth weight of newborn (P > .05) (Table 2).

Similarly associations of Neonatal risk factors with Birth weight of newborn were also studied by chi square $\left(\chi^{2}\right)$ test. It found gestational age at birth was significantly correlated to birth weight of newborn, $\chi^{2}(1, \mathrm{~N}=300)=5.059, \mathrm{P}<.001$, while sex of child, $\chi^{2}(1, \mathrm{~N}=300)=0.008, \mathrm{P}=0.929$, and any congenital malformation present $\chi^{2}(1, \mathrm{~N}=300)=0.511, \mathrm{P}=0.475$ were insignificantly related.

The relative risk estimate is a measure of association between the presence or absence of a risk factor and the occurrence of an event (LBW). The relationship between maternal factors and LBW was examined in the following (Table 3). The relative risk of LBW was more than thrice as high among $<18$ Yrs than among $\geq 18$ Yrs. The odds ratio was 3.06 (95\% CI :1.24 - 3.52) and the 95\% CI for the relative risk ratio does not include 1 , indicating that there is a significant difference in the occurrence of LBW between $<18$ Yrs and $\geq 18$ Yrs.

It found gestational age at birth was significantly correlated to birth weight of newborn, $\chi^{2}(1, N=300)=5.059, P<.001$, while sex of child, $\chi^{2}(1, \mathrm{~N}=300)=0.008, \mathrm{P}=0.929$, and any congenital malformation present $\chi^{2}(1, \mathrm{~N}=300)=0.511, \mathrm{P}=0.475$ were insignificantly related.

The relative risk estimate is a measure of association between the presence or absence of a risk factor and the occurrence of an event (LBW). The relationship between maternal factors and LBW was examined in the following (Table 3). The relative risk of LBW was more than thrice as high among $<18$ Yrs than among $\geq 18$ Yrs. The odds ratio was 3.06 (95\% CI :1.24 - 3.52) and the 95\% CI for the relative risk ratio does not include 1 , indicating that there is a significant difference in the occurrence of LBW between $<18 \mathrm{Yrs}$ and $\geq 18$ Yrs.

Table 3: Bivariate cross frequency of Neonatal Risk Factors influencing low birth weight and chi square Test of Association.

\begin{tabular}{|c|c|c|c|c|c|c|c|}
\hline \multirow{2}{*}{\multicolumn{2}{|c|}{ Neonatal Risk Factors }} & \multicolumn{2}{|c|}{ Birth weight of newborn } & \multirow{3}{*}{\begin{tabular}{|r|} 
Total \\
159 \\
\end{tabular}} & \multirow{4}{*}{$\begin{array}{c}\chi^{2} \text { Value } \\
0.008\end{array}$} & \multirow{4}{*}{$\begin{array}{c}\text { df } \\
1\end{array}$} & \multirow{4}{*}{$\begin{array}{c}\text { P-value } \\
0.929 \mathrm{~N}\end{array}$} \\
\hline & & $<2.5 \mathrm{~kg}$ & $\geq 2.5 \mathrm{~kg}$ & & & & \\
\hline \multirow{2}{*}{ Sex } & Male & 41 & 118 & & & & \\
\hline & Female & 37 & 104 & 141 & & & \\
\hline \multirow{2}{*}{ Gestational age at birth } & >37weeks & 53 & 212 & 265 & \multirow{2}{*}{42.501} & 1 & \multirow{2}{*}{$<.001^{* *}$} \\
\hline & $<37$ weeks & 25 & 10 & 35 & & & \\
\hline \multirow{2}{*}{ Any congenital malformation present } & Yes & 1 & 6 & 7 & \multirow{2}{*}{0.511} & 1 & \multirow{2}{*}{$0.475 \mathrm{NS}$} \\
\hline & No & 77 & 216 & 293 & & & \\
\hline Total & 78 & 222 & 300 & & & & \\
\hline
\end{tabular}

**Highly significant at $\mathrm{P}(<.001)$, NS =Not Significant.

Table 4: Risk Estimates and Odd Ratios Analysis in maternal risk factors for LBW.

\begin{tabular}{|c|c|c|c|c|c|}
\hline \multirow{2}{*}{ Maternal risk factors } & \multirow{2}{*}{\multicolumn{2}{|c|}{ Odd of outcome for LBW }} & \multirow{2}{*}{ OR } & \multicolumn{2}{|c|}{$95 \% \mathrm{CI}$} \\
\hline & & & & Lower & Upper \\
\hline \multirow{2}{*}{ Maternal age } & $<18$ Yrs & 1.00 & \multirow{2}{*}{$3.06^{*}$} & \multirow{2}{*}{1.24} & 3.52 \\
\hline & $\geq 18$ Yrs & 0.33 & & & \\
\hline \multirow{2}{*}{ Birth interval } & $<2$ & 0.42 & \multirow{2}{*}{1.88} & \multirow{2}{*}{0.72} & 4.94 \\
\hline & $\geq 3$ & 0.22 & & & \\
\hline \multirow{2}{*}{ Parity } & Primipara & 0.43 & \multirow{2}{*}{1.64} & \multirow{2}{*}{0.96} & 2.81 \\
\hline & Multipara & 0.26 & & & \\
\hline \multirow{2}{*}{ Height of the mother } & $<145 \mathrm{~cm}$ & 0.62 & \multirow{2}{*}{$2.72^{*}$} & \multirow{2}{*}{1.61} & 4.62 \\
\hline & $\geq 145 \mathrm{~cm}$ & 0.23 & & & \\
\hline
\end{tabular}




\section{Academic Journal of Pediatrics \& Neonatology}

\begin{tabular}{|c|c|c|c|c|c|}
\hline \multirow{2}{*}{ History of abortion } & Yes & 0.39 & 1.15 & 0.57 & 2.31 \\
\hline & No & 0.34 & & & \\
\hline \multirow{2}{*}{$\begin{array}{l}\text { History of chronic } \\
\text { diseases }\end{array}$} & $\begin{array}{c}\text { Gestational } \\
\text { hypertension }\end{array}$ & 0.63 & 1.57 & 0.27 & 9.04 \\
\hline & Gestational diabetes & 0.40 & & & \\
\hline \multirow{2}{*}{ History of ANC visit } & $<4$ & 0.58 & $1.90^{*}$ & 1.03 & 3.52 \\
\hline & $\geq 4$ & 0.31 & & & \\
\hline \multirow{2}{*}{$\begin{array}{l}\text { Iron and calcium } \\
\text { consumption }\end{array}$} & No & 0.50 & 1.44 & 0.35 & 5.90 \\
\hline & Yes & 0.35 & & & \\
\hline \multirow{2}{*}{$\begin{array}{l}\text { Weight gain during } \\
\text { delivery }\end{array}$} & $<6$ & 0.65 & 1.98 & 0.88 & 4.44 \\
\hline & $\geq 6$ & 0.33 & & & \\
\hline \multirow{2}{*}{$\begin{array}{l}\text { History of high risk } \\
\text { behaviour }\end{array}$} & Tobacco & 3.00 & 8.84 & 0.91 & 86.28 \\
\hline & None & 0.34 & & & \\
\hline \multirow{2}{*}{$\begin{array}{l}\text { Status of previous } \\
\text { birth }\end{array}$} & LBW & 0.63 & 2.73 & 0.81 & 9.14 \\
\hline & Normal & 0.23 & & & \\
\hline \multirow{2}{*}{ Type of pregnancy } & Multiple & 2.00 & $5.95^{*}$ & 1.07 & 33.13 \\
\hline & Single & 0.34 & & & \\
\hline
\end{tabular}

Birth interval having $<2$ had higher OR than that of $\geq 3$ (OR=1.88, 95\%CI: 1.24-3.52), Similarly, Primipara Parity had higher OR than that of multipara (OR=1.64, 95\%CI: 0.96-2.81). Similar interpretation was found in case of height of the mother (OR=2.72, 95\%CI: 1.61-4.62), history of abortion (OR=1.15 , 95\%CI: 0.57-2.31), history of chronic diseases $(\mathrm{OR}=1.57,95 \% \mathrm{CI}$ : $0.27-9.04)$, history of $\mathrm{ANC}$ visit(OR=1.90, 95\%CI: 1.03-3.52), iron and calcium consumption (OR=1.44, 95\%CI: 0.35-5.90), weight gain during delivery (OR=1.98, 95\%CI: 0.88-4.44), history of high risk behaviour (OR=8.84, 95\%CI: 0.91-86.28), status of previous birth (OR=2.73, 95\%CI: 0.81-9.14), type of pregnancy (OR=5.95, 95\%CI: 1.07-33.13). (Table 4).

\section{Conclusion}

Globally, more than 20 million infants are born with Low Birth Weight. The major challenge in the field of public health is to identify the factors influencing low birth weight and to institute remedial measures. The study was attempted to assess prevalence of low birth weight and its risk factors affecting low birth weight.

The prevalence of low birth weight was found to be very high and it was associated with many risk factors related to maternal health and services. Among these, Low birth weight was significantly associated with maternal age $<18$ years $\left(\mathrm{p}<0.045^{*}\right.$ ), height of the mother $<145 \mathrm{~cm}\left(<.001^{* *}\right)$, history of ANC visit $<3\left(\mathrm{p}<0.038^{*}\right)$, history of high risk behavior (use of Tobacco) $\left(\mathrm{p}<0.024^{*}\right)$, multiple pregnancy $\left(0.022^{*}\right)$, gestational age $<37$ weeks $\left(\mathrm{p}<.001^{* *}\right)$, normal mode of delivery $\left(\mathrm{p}<0.005^{* *}\right)$.

Hence it is recommended to improve maternal health through strengthening the existing maternal services such as maternal nutrition, and education, at the basic level of community.

\section{Acknowledgement}

I deeply acknowledge Dr A. Bhattacharya, Professor and head, Department of Obstetrics and Gynaecology, Guwahati Medical College Hospital, Assam and Authority of the hospital and Ethical committee of Assam down town University for giving permission to conduct this study.

\section{References}

1. WHO (1984) The incidence of Low Birth Weight: An update. Weekly Epidemiological Research 59: 205-211.

2. WHO Maternal Newborn, Child \& Adolescents Health.

3. Low birth weight in newborn/ symptoms and causes/ Bostom children's Hospital.

4. UNICEF (2004) Low Birth Weight: Country, Regional and Global Estimates. New York, USA, p. 1-9.

5. Karan S, Mathur B, Surender YA (1972) Incidence and causes of perinatal mortality at the institute of child health hospital. Ind Paediatr pp. 99-105.

6. Risnes KR, Vatten LJ, Bakar JL, Jamesson K, Sovio U, et al. (2011) Birthweight and mortality in adulthood: A systemic review and meta analysis. Int J Epidemiol 40(3): 647-661.

7. Larroque B, Bertrais s, Czemichow P, Leger J (2001) School difficulties in 20 years old who were born small for gestational age at term in a regional cohort study. Pediatrics 108(1): 111-115.

8. Low birth weight-wikipedia.

9. UNICEF: Global data (2013) Challenges in minimizing LBW infants in Bihar, India. Stanford University, USA.

10. Krishnatreya Mousumi, Ahmed Sajida, Sarma Kabindra Deva (2015) A study to routine antenatal care and its relationship with birth weight in Dimoria Block, kamrup District, Assam, India 2(11): 1621-1629.

11. Bora M, Agarwalla R (2016) Maternal and socio-demographic determinants of low birth weight (LBW): A community-based study in a rural block of Assam. J postgrad Med 62(3):178-181. 
12. Sengupta Sarthak, Baruah Minaksh (2002) Maternal Bio-social factors affecting birth weight in Ahom of Assam. J Hum Ecol 13(4): 333-334.

13. Biswas R, Dasgupta A, Sinha RN, Chaudhuri RN (2008) An epidemiological study of low birth weight newborns in the district of Puruliya, west Bengal. Indian J Public Health 52(2): 65-71.

14. Kran Agarwal, Ashok Agarwal, Agarwal VK, Pooja Agarwal, Varsha Chaudhury, et al. (2011) Prevalence and Determinats of "low birth weight" among institutional deliveries. Ann Nigerian Med 5(2): 48-52.

15. Rahul Hanumant Dankar, Mahd Shafee, Sati Prasad Sinhna (2014) Prevalence and risk factors affecting low birth weight in adistrict hospital at perambalur, Tamilnadu. Global Journal of medicine and public health 3(2).

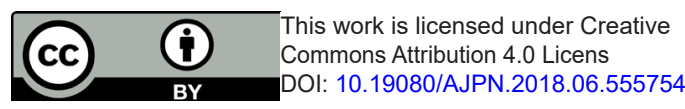

16. Velankar DH (2009) Maternal factors contributing to low birth weight babies in urban slum community of greater Mumbai. Bombay Hospital Journal 51(1):26-35.

17. Kiran A, Garg BS (2000) A study of factors affecting LBW. Indian Journal of Community Medicine 25: 57-62.

18. Balaji Kavitha, Sathish Sankar, Balagi Nandagopal (2010) Low Birth Weight newborns: Magnitude of the problem seen in a 100 bed hospital of a rural area in Vellore District, Tamil Nadu. Indian journal of Community medicine 35(2): 362-364.

\section{Your next submission with Juniper Publishers will reach you the below assets}

- Quality Editorial service

- Swift Peer Review

- Reprints availability

- E-prints Service

- Manuscript Podcast for convenient understanding

- Global attainment for your research

- Manuscript accessibility in different formats

( Pdf, E-pub, Full Text, Audio)

- Unceasing customer service

Track the below URL for one-step submission https://juniperpublishers.com/online-submission.php 